\title{
Características Agronômicas de Cultivares de Milho (Zea mays L.) e Qualidade dos Componentes e Silagem ${ }^{1}$
}

\author{
Sebastião Luiz de Almeida Filho², Dilermando Miranda da Fonseca ${ }^{3}$, Rasmo Garcia ${ }^{3}$, José \\ Antônio Obeid $^{3}$, Jackson Silva e Oliveira ${ }^{4}$
}

\begin{abstract}
RESUMO - Este trabalho foi conduzido para se avaliarem as características agronômicas (acamamento, quebramento e produtividade) e químico-bromatólogicas da matéria verde e silagem de 19 cultivares de milho. Os tratamentos foram aplicados em parcelas de 5 x $4 \mathrm{~m}$ em um delineamento de blocos casualizados, com quatro repetições. Por ocasião da semeadura, aplicaram-se doses correspondentes a $500 \mathrm{~kg} / \mathrm{ha}$ da fórmula 4-14-8 $\left(\mathrm{N}-\mathrm{P}_{2} \mathrm{O}_{5}-\mathrm{K}_{2} \mathrm{O}\right)$ e, aos 47 dias da emergência, $60 \mathrm{~kg} / \mathrm{ha}$ de $\mathrm{N}$ em cobertura. Entre as dezenove cultivares estudadas, selecionaramse, com base na porcentagem de plantas quebradas e acamadas, nove com características agronômicas adequadas para colheita mecanizada. Ao atingirem o estádio grão farináceo, as plantas de milho da área útil $\left(12 \mathrm{~m}^{2}\right)$ foram colhidas e passadas em picadeira, para se obterem partículas de aproximadamente $2 \mathrm{~cm}$. Depois de picada e homogeneizada, aproximadamente $15 \mathrm{~kg}$ de matéria verde foram colocados em sacos plásticos, eliminando o ar e, em seguida, transferidos para uma câmara escura, simulando assim as condições de um silo. A produção de matéria seca dos híbridos selecionados para serem ensilados não apresentou grandes variações, destacando-se o Zeneca 850 e o Braskalb XL380 com 12,72 e 12,62 t/ha de matéria seca, respectivamente. A porcentagem de espiga nas plantas e os teores de fibra em detergente neutro (FDN), fibra em detergente ácido (FDA), carboidratos solúveis e digestibilidade in vitro da matéria seca dos híbridos não diferiram. Contudo, os teores de FDN, FDA, N-NH 3 / NT e DIVMS na silagem mostraram diferenças entre os nove híbridos, o que não se verificou para proteína bruta, ácido láctico e pH.
\end{abstract}

Palavras-chave: composição química, forragem, digestibilidade

\section{Productivity of Maize Cultivars (Zea mays L.) and Quality of Components and Silage}

ABSTRACT - This work was carried out to evaluate the agronomic characteristics (bedding, breakage, and productivity) and the chemical-bromatological of the green matter and silage of 19 cultivars of maize. The treatments were applied on $5 \mathrm{x} 4-\mathrm{m}$ plots arranged in a randomized block design with four replications. By the ocassion of sowing, doses corresponding to $500 \mathrm{~kg} / \mathrm{ha}$ of the formula 4-14$8\left(\mathrm{~N}-\mathrm{P}_{2} \mathrm{O}_{5}-\mathrm{K}_{2} \mathrm{O}\right)$, were applied and at the 47 day of emergency, $60 \mathrm{~kg} / \mathrm{ha}$ of $\mathrm{N}$ in broadcast. From the studied nineteen cultivars, nine were selected based on percentage of broken and bedridden plants with adequate agronomic characteristics to mechanical harvest. When the plants from the useful area $\left(12 \mathrm{~m}^{2}\right)$ reached the dough stage, they were harvested and mechanically chopped, to obtain particles closely to $2 \mathrm{~cm}$. After being chopped and homogenized, nearly $15 \mathrm{~kg}$ of green matter were placed inside plastic bags. After the air being eliminated, they were transferred into a dark chamber, thus simulating a silo condition. Dry matter yield from the selected hybrids to be stored did not present big variation, with Zeneca 850 and Braskalb XL 380 (12.72 and 12.62 t/ha of dry matter, respectively) being the most outstanding. The percentage of ear in the plants and contents of neutral detergent fiber (NDF), acid detergent fiber (ADF) and soluble carbohydrates and dry matter in vitro disappearance (IVDMD) of hybrids did not differ. However, the FDN, FDA, N-NH 3 /NT and IVDMD in the silage showed differences among the nine hybrids, which was not verified for the crude protein, lactic acid, and $\mathrm{pH}$.

Key Words: chemical composition, forage, digestibility

\section{Introdução}

Existe no mercado grande número de cultivares de milho com índices de produtividade e adaptação influenciados pelas condições edafoclimáticas. A identificação de plantas mais adaptadas às condições em que serão cultivadas contribuirá para obtenção de maiores rendimentos da cultura do milho. Sabe-se que, além da genética e do ambiente, a produção é influenciada, entre outros fatores, por qualidade das sementes, época de semeadura, população de plantas, preparo, correção e adubação do solo, controle de plantas daninhas, pragas e doenças, irrigação, entre outros. Contudo, existem poucas informações sobre os efeitos destes fatores sobre a qualidade da forragem produzida.

O milho como recurso forrageiro na forma de silagem tem sido amplamente utilizado, em todo o

\footnotetext{
${ }^{1}$ Parte da Tese de Mestrado do primeiro autor.

2Engenheiro-Agrônomo, Mestre, Técnico da CEPET.

3Professor do DZO/UFV.

${ }^{4}$ Pesquisador da EMBRAPA.
} 
ALMEIDA FILHO et al.

mundo, na alimentação de bovinos de leite e corte. O seu potencial para ensilagem é evidenciado, nos Estados Unidos, pela produtividade de até $23 \mathrm{t} / \mathrm{ha}$ de matéria seca, em condições experimentais. No Brasil, têm-se obtido, em áreas mais restritas, elevados rendimentos com a utilização de alta tecnologia. Entretanto, esta não tem sido a realidade nas diversas regiões de pecuária de leite, onde a produtividade freqüentemente é baixa (FERREIRA, 1990).

Segundo STRUIK (1983), o aumento de produção de matéria seca, sem preocupação com maior participação de espiga na massa total, pode reduzir a qualidade da silagem. Entretanto, JOHNSON et al., 1985, nos Estados Unidos, e DEINUM et al., 1984, na França, mostraram que nem sempre a maior proporção de grãos na forragem confere melhor qualidade à silagem. Segundo esses autores, a qualidade do grão e da fração verde da planta (caule, folha, e palha), combinada com o percentual de cada uma dessas partes na planta, determina o valor nutritivo do material colocado dentro do silo.

O teor de carboidratos solúvel na forragem a ser ensilada contribui para a produção de ácidos orgânicos, principalmente ácido láctico, que são importantes para obtenção de boa silagem (LOPES, 1975). A acidez atua controlando ou inibindo o desenvolvimento de microrganismos prejudiciais e também da própria atividade das bactérias produtoras de ácido láctico, que cessam o crescimento e a ação a partir de determinado valor de $\mathrm{pH}$, em geral, em torno de 4,0 (RUIZ e RUIZ, 1990). Para ácido láctico, Whintlembury et al. (1967), citados por TOSI (1973), consideram o mínimo de $6 \%$, na matéria seca, para boa preservação da silagem de gramíneas. A presença de nitrogênio amoniacal também é uma característica importante na avaliação da silagem, pois contribui para elevação do $\mathrm{pH}$, sendo, por isso, indicativo de fermentação indesejável (Miller et al., 1961, citado por VALENTE, 1977).

Este trabalho foi realizado com o objetivo de avaliar cultivares de milho quanto às características agronômicas e químico-bromatológicas das plantas e da silagem.

\section{Material e Métodos}

O experimento foi desenvolvido no sítio Boa Vista, em Coimbra, em uma área plana de solo Podzólico Vermelho-Amarelo, câmbico, fase terraço, textura argilosa. A análise do solo revelou as seguintes características químicas: $\mathrm{pH}-5,6$; P-4,5 mg/dm 3 ; K-58 mg/dm $3 \mathrm{Al}^{+++}-0,0 ; \mathrm{Ca}^{++}{ }_{-}$
$1,5 \mathrm{cmol}_{\mathrm{c}} / \mathrm{dm}^{3} ; \mathrm{Mg}-0,7 \mathrm{cmol}_{\mathrm{c}} / \mathrm{dm}^{3} ; \mathrm{H}+\mathrm{Al}-0,6 \mathrm{cmol}_{\mathrm{c}} / \mathrm{dm}^{3} ;$ e V (saturação de bases)-79,8\%.

Em parcelas de $5 \times 4 \mathrm{~m}$, foram avaliadas 19 cultivares de milho (Tabela 1) que fizeram parte de um projeto de avaliação de milho para silagem coordenado pela EMBRAPA/CNPGL (1997). O delineamento experimental foi de blocos casualizados com quatro repetições sendo as médias comparadas pelo teste Neuman Keul's em nível de 5\%.

Para o estabelecimento da cultura de milho, a área foi arada e posteriormente gradeada para destorroamento, nivelamento e abertura de sulcos. Por ocasião da semeadura, em sulcos espaçados de $1 \mathrm{~m}$, aplicou-se a dose correspondente a $500 \mathrm{~kg} / \mathrm{ha}$, da fórmula 4-14-8 $\left(\mathrm{N}-\mathrm{P}_{2} \mathrm{O}_{5}-\mathrm{K}_{2} \mathrm{O}\right)$. Depois da emergência, até aos 30 dias, foram efetuadas duas aplicações de inseticidas para controle de lagarta (Spodoptera frugiperda). Vinte e dois dias após a emergência, procedeu-se ao desbaste das plantas deixando-se uma população, dependendo da cultivar e de acordo com a recomendação do produtor de sementes, entre 50.000 e 60.000 plantas/ha.

Decorridos 20 dias da emergência, foi feita capina manual na área experimental. Aos 47 dias, realizou-se adubação em cobertura com a dose correspondente a $60 \mathrm{~kg} / \mathrm{ha}$ de nitrogênio. Por ocasião da colheita, com os grãos no estádio farináceo, em seis plantas, ao acaso, foi medida e anotada a altura até o início da inserção da folha bandeira. O número de plantas quebradas, não-possíveis de serem colhidas mecanicamente, foi contado e registrado, cujos valores foram transformados em porcentagem (número de plantas quebradas/número total de plantas, na área útil da parcela). Para o acamamento foram consideradas plantas com mais de $15 \%$ de inclinação em relação ao solo, sendo atribuídas notas de $0,1,2,3,4$ e 5 correspondentes, respectivamente, a $0,20,40,60,80$ e $100 \%$ de plantas acamadas na área útil da parcela.

$\mathrm{Na}$ parcela $(5 \times 4 \mathrm{~m})$ foram colhidas, da área útil $\left(12 \mathrm{~m}^{2}\right)$, as três linhas centrais, desprezando-se $1 \mathrm{~m}$ em cada uma de suas extremidades. Após o corte das plantas a $10 \mathrm{~cm}$ do solo e pesagem da massa verde, todo material foi picado em tamanho aproximado de $2 \mathrm{~cm}$ por meio de picadeira de forragens. Da forragem picada retirou-se amostra (500 g) para secagem em estufa a $60^{\circ} \mathrm{C}$ com ventilação forçada, até a obtenção do peso constante, que depois de secada foi passada em moinho tipo "Willey", compeneira de $1 \mathrm{~mm}$. Parte do material foi armazenada para posteriores análises de fibra em detergente neutro (FDN), fibra em detergente ácido (FDA), carboidratos solúveis 
Rev. bras. zootec.

(CHO) e digestibilidade in vitro da matéria seca (DIVMS), segundo SILVA (1990).

Em função das características de acamamento e quebramento, das 19 cultivares de milho, selecionaram-se nove, que foram ensiladas em condições de laboratório, sendo posteriormente analisadas as composições químico-bromatológicas de suas silagens. A silagem de cada material foi feita com, aproximadamente, $15 \mathrm{~kg}$ da forragem picada, colocada em sacos de polietileno branco e fechados após a eliminação do ar de seu interior e armazenadas em câmara escura.

Após 120 dias, os sacos foram abertos e uma amostra de aproximadamente $1 \mathrm{~kg}$ foi retirada após a homogeneização da silagem. Essa amostra foi dividida em duas partes iguais, sendo uma delas congelada a $-10^{\circ} \mathrm{C}$ para análise de ácido láctico, segundo metodologia de WILSON (1971), e amônia e pH, conforme SILVA (1990). A outra amostra foi secada em estufa com ventilação forçada a $55^{\circ} \mathrm{C}$ durante 72 horas, moída em moinho tipo "Willey" (peneira $1 \mathrm{~mm}$ ) e armazenada para posterior análise quanto aos teores de proteína bruta, FDN, FDA e DIVMS, segundo metodologia proposta por SILVA (1990).

\section{Resultados e Discussão}

A altura das plantas variou entre 1,50 e 1,98 m, tendo a cultivar Embrapa 106 (1,98 m) e Zeneca 8447 (1,96 m) apresentado os maiores valores, os quais não diferiram estatisticamente de outras 15 cultivares, com alturas variando de 1,68 a 1,87 m. Outra característica utilizada na avaliação das cultivares foi o acamamento de plantas, sendo que oito híbridos (Agroceres 1051, Zeneca 8501, Agroceres 5011, Braskalb XL 380, Embrapa 206, Pioneer 3071, Zeneca 8447 e Embrapa HT-2X) não apresentaram planta acamada, o Cargill C-435 teve apenas $2,5 \%$ de acamamento e as demais apresentaram mais de $15 \%$ (Tabela 1 ).

Para plantas quebradas, seis cultivares tiveram porcentagem zero, enquanto os híbridos Embrapa 206, Cargill C-435 e Zeneca 8447, com 0,7; 1,0; e $1,7 \%$, respectivamente, apresentaram os menores valores (Tabela 1). Observa-se que as cultivares de menor acamamento foram as que menos quebraram. Estas características favorecem a colheita mecânica e reduzem perdas no campo. A altura de planta nem sempre parece estar muito relacionada ao

Tabela 1 - Altura de plantas, percentagem de plantas acamadas (PA) e plantas quebradas (PQ) e idade das plantas de 19 cultivares de milho no momento da colheita

Table 1 - Plants height, percentage of bedridden and broken plants, and age of the 19 maize cultivars at harvest

\begin{tabular}{lcccc}
\hline Cultivar & $\begin{array}{c}\text { Altura }(\mathrm{m}) \\
\text { Height }\end{array}$ & PA $(\%)$ & PQ $(\%)$ & $\begin{array}{c}\text { Idade (dias) } \\
\text { Age (days) }\end{array}$ \\
\hline Agroceres 1051 & $1,87 \mathrm{ab}$ & 0 & 0 & 100 \\
Embrapa 205 & $1,81 \mathrm{ab}$ & 15 & 2,5 & 100 \\
Zeneca 8501 & $1,83 \mathrm{ab}$ & 0 & 0 & 99 \\
Embrapa 201 & $1,84 \mathrm{ab}$ & 20 & 5,7 & 100 \\
Embrapa 106 & $1,98 \mathrm{a}$ & 15 & 5,3 & 99 \\
Agroceres 5011 & $1,50 \mathrm{c}$ & 0 & 0 & 96 \\
CargillC-166 & $1,81 \mathrm{ab}$ & 20 & 8 & 90 \\
BraskalbXL380 & $1,79 \mathrm{ab}$ & 0 & 0 & 100 \\
Embrapa 206 & $1,75 \mathrm{abc}$ & 0 & 0,7 & 96 \\
Agrômen 2010 & $1,69 \mathrm{abc}$ & 20 & 4 & 99 \\
CargillC-435 & $1,81 \mathrm{ab}$ & 2,5 & 1 & 92 \\
Braskalb XL222 & $1,62 \mathrm{c}$ & 35 & 10,7 & 90 \\
Agrômen 2007 & $1,80 \mathrm{ab}$ & 30 & 12,3 & 89 \\
Pioneer3071 & $1,68 \mathrm{abc}$ & 0 & 0 & 89 \\
Zeneca 8447 & $1,96 \mathrm{a}$ & 0 & 1,7 & 92 \\
Embrapa HT-2X & $1,74 \mathrm{abc}$ & 0 & 0 & 92 \\
Embrapa CMS-473 & $1,73 \mathrm{abc}$ & 60 & 21 & 86 \\
Pioneer 3071 & $1,75 \mathrm{abc}$ & 15 & 4,5 & 86 \\
Embrapa92HD-1 & $1,75 \mathrm{abc}$ & 60 & 16,7 & 86 \\
CV(\%) & 6,8 & - & - & - \\
\hline Média, & & & & \\
\hline
\end{tabular}

Médias, na coluna, seguidas de letras diferentes são diferentes $(P<0,05)$ pelo teste Neuman Keul.

Means, within a column, followed by different letters are different $(P<.05)$ by Neuman Keul test. 
acamamento, pois o Zeneca 8447 com 1,96 m apresentou zero de acamamento, enquanto o Braskalb XL222 e o Agrômen 2010, com 1,62 e 1,69 m, mostraram 35 e $20 \%$ de plantas acamadas, respectivamente.

As produções de matéria seca dos nove híbridos selecionados não diferiram estatisticamente, tendo os valores variado entre $12,72 \mathrm{e} 10,35 \mathrm{t} / \mathrm{ha}$, respectivamente, para o Zeneca 8501 e Embrapa HT-2X (Tabela 2). Estes rendimentos, mesmo dos híbridos mais produtivos, são muito inferiores às 22,8 e 18,7 t/ha obtidas por JOHNSON et al. (1985) e PEREIRA (1991). Entretanto, são valores bem próximos das 14,7 t/ha alcançadas por VALENTE (1977). Os menores índices de produtividade dos híbridos avaliados neste trabalho, em parte, podem ser atribuídos a déficit hídrico observado entre o $20^{\circ}$ e o $45^{\circ}$ dia após a emergência das plantas.

Os teores de matéria seca nas plantas no momento da colheita variaram de 27,61 a $33,99 \%$ com diferenças significativas $(\mathrm{P}<0,05)$ entre os híbridos (Tabela 2). Entretanto, verifica-se que estes valores, em geral, são bem próximos aos 30 e 35\% recomendados por SILVEIRA (1975) como adequados para o momento da ensilagem. Constata-se que nenhum dos híbridos apresentou umidade acima de 75\%, o que favoreceria o desenvolvimento de bactérias do gênero Clostridium, produtoras de ácido butírico, que levam, em geral, a silagens de péssima qualidade e perdas no valor nutritivo.

Quanto à porcentagem de espiga na matéria seca, embora com grande variação entre os híbridos, 37,12 a 52,33\%, os valores não diferem estatisticamente (Tabela 2). Estas proporções de espiga na matéria seca são iguais ou superiores aos valores de
39 a $41 \%$ para os híbridos Markant, Splenda e Brutus, relatados por STRUIK (1983). Esse autor e FERREIRA (1990) realçam a importância da maior participação da espiga na melhoria do valor nutritivo da forragem. Neste contexto, DEINUM et al. (1984) observaram valores de digestibilidade da matéria orgânica da espiga, com grão no estádio farináceo de até $85 \%$. Portanto, a maior participação da espiga é desejável como característica que pode influir na melhoria da qualidade da forragem e de sua silagem. No entanto, JOHNSON et al. (1985) ressalta que a melhoria da qualidade da silagem também está relacionada à maior qualidade de todos os componentes da planta de milho.

Já os teores de proteína bruta na matéria seca das plantas de milho diferiram estatisticamente com valores entre 5,7 e $8,22 \%$, tendo o maior teor sido observado para o híbrido Agroceres 1051 (Tabela 2). Estes valores de proteína, na planta inteira, são semelhantes aos encontrados por VALENTE (1977), para o milho Maya IX e Dentado Composto, com 7,1 e 7,2\%, respectivamente, e superiores aos dados de HUNT et al. (1993) para os híbridos Pioneer 3377 e 3389 com 5,5 e $5,9 \%$ respectivamente. JOHNSON et al. (1985), também trabalhando com vários híbridos, encontraram teores de proteína na planta inteira de 7,6 a 8,4\%.

Por outro lado, a FDN na matéria seca dos nove híbridos com variação entre 58,13 e 63,39\% não diferiram entre si (Tabela 2). Estes valores são bem superiores aos relatados por HUNT et al. (1993) para os híbridos Pioneer 3377 e 3389, com 42,7 e 48,1\%, respectivamente. A maior participação de grãos nos híbridos americanos pode ter contribuído para diminuir os teores de FDN. Também, segundo STRUIK

Tabela 2 - Produção e percentagem de matéria seca, espiga, proteína bruta, fibra em detergente neutro (FDN), fibra em detergente ácido (FDA), carboidratos solúveis $(\mathrm{CHO})$ e digestibilidade in vitro da matéria seca (DIVMS) dos híbridos de milho

Table 2 - Production and percentage of dry matter, ear, crude protein, neutral detergent fiber (NDF), acid detergent fiber (ADF), soluble carbohydrates (SC) and dry matter in vitro digestibility (DMIVD) of maize hybrids

\begin{tabular}{|c|c|c|c|c|c|c|c|c|}
\hline $\begin{array}{l}\text { Híbrido } \\
\text { Hybrid }\end{array}$ & & $\begin{array}{l}\text { MS } \\
D M\end{array}$ & $\begin{array}{c}\text { Espiga } \\
\text { Ear }\end{array}$ & $\begin{array}{l}\mathrm{PB} \\
C P\end{array}$ & $\begin{array}{l}\text { FDN } \\
N D F\end{array}$ & $\begin{array}{l}\text { FDA } \\
A D F\end{array}$ & $\begin{array}{c}\mathrm{CHO} \\
S C \\
\end{array}$ & $\begin{array}{l}\text { DIVMS } \\
D M I V D\end{array}$ \\
\hline & $-\mathrm{t} / \mathrm{ha}-$ & & & & $(\%)$ & & & \\
\hline Zeneca 8501 & $12,72 \mathrm{a}$ & $33,08 \mathrm{ab}$ & $41,34 \mathrm{a}$ & $6,99 \mathrm{ab}$ & $58,94 \mathrm{a}$ & $29,47 \mathrm{a}$ & $18,42 \mathrm{ab}$ & $54,72 \mathrm{a}$ \\
\hline Braskalb XL380 & $12,62 \mathrm{a}$ & $29,48 b c$ & $43,01 \mathrm{a}$ & $6,01 \mathrm{ab}$ & $61,64 a$ & $30,31 \mathrm{a}$ & $15,67 \mathrm{ab}$ & $55,33 \mathrm{a}$ \\
\hline Agroceres 5011 & $12,11 \mathrm{a}$ & $31,99 \mathrm{ab}$ & $43,75 \mathrm{a}$ & $7,50 \mathrm{ab}$ & $60,93 \mathrm{a}$ & $30,10 a$ & $18,80 \mathrm{ab}$ & $55,52 \mathrm{a}$ \\
\hline Embrapa 206 & $11,96 a$ & $30,66 \mathrm{abc}$ & $38,94 \mathrm{a}$ & $6,53 \mathrm{ab}$ & $58,13 \mathrm{a}$ & $28,89 a$ & $20,20 a$ & $55,38 \mathrm{a}$ \\
\hline Cargill 435 & $11,74 \mathrm{a}$ & $33,99 a$ & $37,12 \mathrm{a}$ & $6,11 \mathrm{ab}$ & $62,25 \mathrm{a}$ & $30,51 \mathrm{a}$ & $15,34 \mathrm{ab}$ & $53,40 \mathrm{a}$ \\
\hline Agroceres 1051 & $11,25 \mathrm{a}$ & $27,61 \mathrm{c}$ & $51,76 \mathrm{a}$ & $8,22 \mathrm{a}$ & $63,39 a$ & $30,04 a$ & $17,00 \mathrm{ab}$ & $53,15 \mathrm{a}$ \\
\hline Pioneer 3071 & $10,93 \mathrm{a}$ & $32,55 \mathrm{ab}$ & $50,03 \mathrm{a}$ & $8,12 \mathrm{ab}$ & $59,75 \mathrm{a}$ & $29,80 a$ & $17,80 \mathrm{ab}$ & $56,86 \mathrm{a}$ \\
\hline Zeneca 8447 & $10,52 \mathrm{a}$ & $33,14 \mathrm{ab}$ & $52,33 \mathrm{a}$ & $7,41 \mathrm{ab}$ & $61,09 a$ & $31,75 \mathrm{a}$ & $14,49 \mathrm{~b}$ & $55,89 a$ \\
\hline EmbrapaHT-2X & $10,35 \mathrm{a}$ & $30,83 \mathrm{abc}$ & $45,94 \mathrm{a}$ & $5,70 \mathrm{~b}$ & $61,27 a$ & $30,94 \mathrm{a}$ & $13,70 \mathrm{~b}$ & $54,04 \mathrm{a}$ \\
\hline$\overline{\mathrm{CV}}(\%)$ & 10,73 & 5,88 & 14,77 & 14,89 & 4,09 & 5,40 & 14,44 & 3,13 \\
\hline
\end{tabular}

Médias, na coluna, seguidas de letras diferentes são diferentes $(P<0,05)$ pelo teste Neuman Keul.

Means, within a column, followed by different letters are different $(P<.05)$ by Neuman Keul test. 
(1983), temperaturas altas durante o desenvolvimento da cultura podem elevar os teores de FDN na planta. De modo semelhante, os teores de FDA, que inclui a parte da fibra lignificada e indigestível da forragem, com valores entre 28,89 e $31,75 \%$, não apresentaram diferenças entre os híbridos (Tabela 2). HUNT et al. (1993) relataram valores de 26,3 e $30 \%$ de FDA para Pioneer 3377 e 3389, respectivamente, que são valores próximos aos encontrados neste trabalho.

Os teores de carboidratos solúveis na planta tiveram grande variação $(13,70$ a 20,20$)$, sendo o maior valor para o híbrido Embrapa 206, que não diferiu dos de outros seis híbridos, cujas porcentagens variaram entre 15,34 e 18,80\% (Tabela 2). Estes teores de carboidratos solúveis estão bem acima dos 6 a $8 \%$ sugeridos por WOOLFORD (1972) para proporcionar intensa fermentação láctica. Todavia, são iguais ou superiores aos $15 \%$ estabelecidos por JOHNSON JR. et al. (1971) e OBEID et. al. (1992) como teor mínimo na matéria seca da forragem.

Com relação à DIVMS os valores entre 53,15 e $56,86 \%$ não diferiram (Tabela 2). Estes valores de DIVMS são inferiores aos dos híbridos americanos Pioneer 3055, Pioneer 3147 e Americus Seed ASC99 com 67,$2 ; 61,6$; e 64,8\%, respectivamente, descritos por JOHNSON JR. et al. (1985). Isto mostra, claramente, a necessidade de se melhorar o valor nutritivo das cultivares de milho a serem ensiladas.

Os teores de proteína bruta nas silagens dos nove híbridos são estatisticamente iguais, com os valores variando entre 5,99 e 6,71\% (Tabela 3). Estes valores de proteína das silagens são próximos aos 6,7\% encontrados por PURGER e LOPEZ (1980) e inferiores aos 7,3 e 7,1\% relatados por LEMPP (1986) e PEREIRA (1991), respectivamente. Já DEINUM et al. (1984) encontraram para o híbrido LG-11, no estádio farináceo, $8,7 \%$. De fato, as silagens são alimentos considerados energéticos e, portanto, com baixos teores de proteína. Quando estes são inferiores a 7\%, o consumo e a digestibilidade dos nutrientes são influenciados, segundo RUIZ e RUIZ (1990), por deficiência de nitrogênio no rúmen.

A digestibilidade in vitro da matéria seca das silagens apresentou valores entre 51,55 e 56,20\%, que diferiram entre si $(\mathrm{P}<0,05)$, tendo o híbrido Pioneer 3071 apresentado a maior digestibilidade $(56,20 \%) \mathrm{e}$ o Agroceres 5011 (51,55\%), a menor (Tabela 3). Estes resultados de DIVMS são inferiores aos 61,4\% encontrados por OBEID et al. (1992) e, na maioria, superiores aos $51,8 \%$ determinados por EVANGELISTA et al. (1991) para silagem de milho.

A FDN na matéria seca das silagens, com variação entre 46,51 e 52,74\% mostram diferenças estatísticas $(\mathrm{P}<0,05)$, sendo o maior valor para o híbrido Pioneer 3071 com 52,74\%, que é estatisticamente igual aos teores apresentados pelas sete outras silagens, com valores variando de 48,39 a 52,61\% (Tabela 3). Estes teores de FDN nas silagens são semelhantes aos dos híbridos $3369 \mathrm{H}$ e X304C com 46,80 e $55,40 \%$, respectivamente, relatados por

Tabela 3 - Teores de proteína bruta (PB), digestibilidade in vitro da matéria seca (DIVMS), fibra em detergente neutro (FDN), fibra em detergente ácido (FDA), nitrogênio amoniacal $\left(\mathrm{N}-\mathrm{NH}_{3} / \mathrm{NT}\right)$, ácido láctico e $\mathrm{pH}$ das silagens dos híbridos de milho

Table 3 - Crude protein contents, dry matter in vitro digestibility (DMIVD), neutral detergent fiber(NDF), acid detergent fiber (ADF), ammoniac nitrogen $\left(\mathrm{N}-\mathrm{NH}_{3} / \mathrm{NT}\right)$, lactic acid and $\mathrm{pH}$ of maize hybrids silage

\begin{tabular}{|c|c|c|c|c|c|c|c|}
\hline $\begin{array}{l}\text { Híbrido } \\
\text { Hybrid }\end{array}$ & $\begin{array}{l}\text { PB } \\
C P\end{array}$ & FDN & $\begin{array}{l}\text { FDA } \\
N D F\end{array}$ & $\begin{array}{c}\mathrm{N}-\mathrm{NH}_{3} / \mathrm{NT} \\
A D F \\
\end{array}$ & $\begin{array}{l}\text { Ác. lático } \\
\text { Lactic acid }\end{array}$ & $\begin{array}{l}\text { DIVMS } \\
\text { DMIVD }\end{array}$ & $\mathrm{pH}$ \\
\hline & & & $-(\%$ & & & 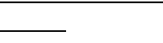 & \\
\hline Zeneca 8501 & $6,19 a$ & $48,74 \mathrm{ab}$ & $29,20 \mathrm{ab}$ & $8,82 \mathrm{abc}$ & $4,09 \mathrm{a}$ & $53,58 \mathrm{abc}$ & $3,46 a$ \\
\hline Braskalb XL380 & $5,99 a$ & $49,67 \mathrm{ab}$ & $29,35 \mathrm{ab}$ & $8,34 \mathrm{ab}$ & $4,22 \mathrm{a}$ & $55,33 \mathrm{ab}$ & $3,37 \mathrm{a}$ \\
\hline Agroceres 5011 & $6,16 a$ & $46,51 b$ & $28,87 \mathrm{ab}$ & $9,02 \mathrm{abc}$ & $4,22 \mathrm{a}$ & $51,55 \mathrm{c}$ & $3,45 \mathrm{a}$ \\
\hline Embrapa 206 & $6,71 \mathrm{a}$ & $50,93 \mathrm{a}$ & $30,40 \mathrm{ab}$ & $8,20 \mathrm{bc}$ & $4,44 \mathrm{a}$ & $53,08 \mathrm{abc}$ & $3,37 \mathrm{a}$ \\
\hline Cargill 435 & $6,49 a$ & $52,61 \mathrm{a}$ & $31,53 \mathrm{a}$ & $7,74 \mathrm{bc}$ & $4,08 \mathrm{a}$ & $52,36 \mathrm{bc}$ & $3,48 \mathrm{a}$ \\
\hline Agroceres 1051 & $6,11 \mathrm{a}$ & $51,80 \mathrm{a}$ & $31,84 \mathrm{a}$ & $10,23 \mathrm{a}$ & $4,25 \mathrm{a}$ & $53,54 \mathrm{ab}$ & $3,47 a$ \\
\hline Pioneer 3071 & $6,51 \mathrm{a}$ & $52,74 \mathrm{a}$ & $31,16 \mathrm{ab}$ & $8,04 \mathrm{bc}$ & $4,31 \mathrm{a}$ & $56,20 \mathrm{a}$ & $3,48 \mathrm{a}$ \\
\hline Zeneca 8447 & $6,09 \mathrm{a}$ & $48,39 \mathrm{ab}$ & $27,60 \mathrm{~b}$ & $7,61 \mathrm{bc}$ & $3,84 \mathrm{a}$ & $52,70 \mathrm{abc}$ & $3,44 \mathrm{a}$ \\
\hline Embrapa HT-2X & $6,70 a$ & $52,14 \mathrm{a}$ & $30,58 \mathrm{ab}$ & $7,46 \mathrm{c}$ & $4,42 \mathrm{a}$ & $52,71 \mathrm{abc}$ & $3,38 \mathrm{a}$ \\
\hline $\mathrm{CV}(\%)$ & 9,24 & 4,46 & 5,57 & 9,46 & 8,9 & 2,91 & 2,34 \\
\hline
\end{tabular}

Médias, na coluna, seguidas de letras diferentes são diferentes $(P<0,05)$ pelo teste Neuman Keul.

Means, within a column, followed by different letters are different $(P<.05)$ by Neuman Keul test. 
JOHNSON et al. (1985). Observa-se, ainda, que as porcentagens de FDN na forragem antes de ser ensilada (Tabela 2) foram sempre superiores às de suas respectivas silagens (Tabela 3 ), o que se deve, provavelmente, a perdas de constituintes da parede celular, conforme relatos por HUNT et al. (1993), que encontraram diminuição de componentes da parede celular em silagens de híbridos de milho, quando comparada à forragem natural, principalmente, de celulose e hemicelulose, porém não na magnitude verificada neste trabalho.

Para os teores de FDA nas silagens dos híbridos, foram constatadas diferenças estatísticas $(\mathrm{P}<0,05)$, sendo o maior valor encontrado para a silagem do híbrido Agroceres 1051 (31,84\%) e o menor para o Zeneca 8447 (27,60\%).

Com relação ao nitrogênio amoniacal, em porcentagem do nitrogênio total, houve diferenças $(\mathrm{P}<0,05)$ entre as silagens dos nove híbridos, tendo o maior valor sido observado na silagem do Agroceres 1051 com 10,23\%, que não diferiu dos teores de amônia de outros três, que variaram de 8,34 a $9,02 \%$ (Tabela 3). Estes valores são superiores aos relatados por VALENTE (1977), que encontrou teores de nitrogênio amoniacal na matéria seca das silagens de milho com boa conservação, variando de 4,7 a 5,3\%. Para RUIZ e RUIZ (1990), silagens com 7 a $8 \%$ de nitrogênio amoniacal são classificadas como excelentes e as com 9 a $10 \%$, como boa.

Os teores de ácido láctico na matéria seca das silagens também apresentaram pequenas variações (3,84 a 4,44\%), sendo estatisticamente iguais (Tabela $3)$. Estes valores são semelhantes aos encontrados por TAYAROL MARTIN (1981) e BLOCK et al. (1992), 4,51 e 4,89\%, respectivamente, e inferiores aos 6,09 e 6,0\% encontrados por HUNT et al. (1993).

$\mathrm{O} \mathrm{pH}$ das silagens dos nove híbridos com valores 3,37 e 3,48 não mostraram diferenças significativas. Estes dados de pH estão bem próximos aos 3,7 relatados por VALENTE (1977) para o milho Maya IX e Dentado Composto VIII. Todas silagens apresentaram aspectos visuais de boa conservação, com ausência de fungos (bolor), coloração amarronzada e cheiro agradável. Segundo RUIZ e RUIZ (1990), as silagens são classificadas como excelentes, quando o pH é menor que 4,6 para teores de matéria seca, variando de 26 a $35 \%$, o que foi observado para todas as silagens dos nove híbridos (Tabela 3 ).

\section{Conclusões}

Entre as dezenove cultivares de milho, apenas nove híbridos apresentaram características agronômi- cas adequadas para serem colhidas mecanicamente.

Os nove híbridos de milho selecionados apresentaram baixa produtividade $(10,35$ a $12,72 \mathrm{t} / \mathrm{ha}) \mathrm{de}$ matéria seca.

Os teores de fibra em detergente neutro, fibra em detergente ácido e digestibilidade in vitro da matéria seca dos nove híbridos, no estádio farináceo, não mostraram diferenças, enquanto os de carboidratos solúveis variaram de 13,70 a 18,42\%.

A proteína bruta, o ácido láctico e o $\mathrm{pH}$ da silagem apresentaram pequenas variações entre os nove híbridos. Os teores de fibra em detergente neutro, fibra em detergente ácido e digestibilidade in vitro da matéria seca da silagem apresentaram as maiores diferenças entre os híbridos selecionados.

\section{Referências Bibliográficas}

BLOCK, E., MULlER, L.D., KILMER, L.H. 1992. Brown midrib - 3 versus normal corn plants (Zea mays L.) harvest as whole plant or stover and frozen fresh or preserved as silage for sheep. Can. J. Anim. Sci., 62(2):487-498.

DEINUM, B., STEG, A., HOF, G. 1984. Measurement and prediction of digestibility of forage maize in the Netherlands. Anim. Feed. Sci. Technol., 10(4):301-313.

EMPRESA BRASILEIRA DE PESQUISA AGROPECUÁRIA. Avaliação de cultivares de milho para silagem - Safra 94/95, relatório: Juiz de Fora: CNPGL/EMBRAPA, 1997. 18p.

EVANGELISTA, A.R., GARCIA, R., OBEID, J.A. et al. 1991. Consórcio milho-soja: rendimento forragem, qualidade e valor nutritivo das silagens. R. Soc. Bras. Zootec., 20(6):578-584.

FERREIRA, J.J. 1990. Aspectos vegetativos da planta de milho e momento da colheita para ensilagem. Inf. Agropec., 14(164):47-49.

HUNT, C.W., KEZAR, W., HINMAN, D.D. et al. 1993. Effects of hybrid and ensiling and without a microbial inoculant on the nutritional characteristics of whole-plant corn. J. Anim. Sci., 71(1):38-43.

JOHNSON JR., J.C., MONSON, W.G., PETLIGREW, W.T. 1985. Variation in nutritive value of corn hybrids for silage. Nutr. Rep. Int., 32(4):953-958.

JOHNSON, R.R., FARIA, U.P., McCLURE, K.E. 1971. Effects of maturity on chemical composition and digestibility of bird resistant sorghum plants when fed to sheep as silage. J. Anim. Sci., 33(5):1102-1109.

LEMPP, B. Avaliação do valor nutritivo da silagem de milho e dos fenos de capim-colonião e capim-jaraguá para vacas em lactação. Viçosa, MG: UFV, 1986. 58p. Dissertação (Mestrado em Zootecnia) - Universidade Federal de Viçosa, 1986.

LOPES, J. Valor nutritivo de silagens. In: SIMPÓSIO SOBRE MANEJO DE PASTAGEM, 2, 1975, Piracicaba. Anais... Piracicaba: ESALQ, 1975. p. 187-218.

OBEID, J.A., GOMIDE, J.A., CRUZ, M.E. et al. 1992. Silagem consorciada de milho (Zea mays, L.) com leguminosas: produção e composição bromatológica. R. Soc. Bras. Zootec., 21(1):33-38.

PEREIRA, O.P. Produtividade do milho (Zea Mays L.), do sorgo (Sorghum bicolor (L.) Moench), da aveia (Avena sativa), do milheto (Pennisetum americanum L.) e do híbrido (S. bicolor 
Rev. bras. zootec.

XS. sudanense) e respectivos valores nutritivos sob a forma de silagem e verde picado. Viçosa, MG: UFV, 1991. 86p. Dissertação (Mestrado em Zootecnia) - Universidade Federal de Viçosa, 1991.

PURGER, J.V.N, LOPEZ, J. 1980. Avaliação química e "in vivo" da silagem de milho (Zea mays) sem e com suplementação nitrogenada. R. Soc. Bras. Zootec., 9(3):360-372.

RUIZ, E.M., RUIZ, A. Metodologias para invetigaciones sobre conservación y utilización de ensilajes. In: INSTITUTO INTERAMERICANO DE COOPERACIÓN PARA LA AGRICULTURA - IICA. Nutricion de ruminantes: guia metodológico de cooperación. San José: 1990. p.179-218.

SILVA, D. J. 1990. Análise de alimentos. Métodos químicos e biológicos. Viçosa, MG, Impr. Univ. 166p.

SILVEIRA, A.C. Técnicas para produção de silagens. In: SIMPÓSIO SOBRE MANEJO DE PASTAGEM, 2, 1975, Piracicaba. Anais... Piracicaba: ESALQ, 1975. p. 156-186.

STRUIK, P.C. 1983. Physiology of forage maize (Zea mays L.) in relation to its production and quality. Wageningen: Pudoc. $252 \mathrm{p}$.

TAYAROL MARTIN, L.C. Efeito da associação milho-soja (Glycine $\max ($ L.) Merrill), na quantidade da silagem $e$ desenvolvimento de novilhos. Viçosa, MG: UFV, 1981. 52p. Dissertação (Mestrado em Zootecnia) - Universidade Federal de Viçosa, 1981.
TOSI, H., Conservação de forragem como conseqüência do manejo. In: SIMPÓSIO SOBRE MANEJO DE PASTAGEM, 1, 1973, Piracicaba. Anais... Piracicaba: ESALQ, 1973. p. 117-40.

VALENTE, J.O. Produtividade de duas variedades de milho e quatro variedades de sorgo e valor nutritivo de suas silagens. Viçosa, MG: UFV, 1977. 76p. Dissertação (Mestrado em Zootecnia) - Universidade Federal de Viçosa, 1977.

WILSON, R.K. A rapid accurate method for measuring volatile fatty acids and latic acid in silage. Dublin: Agricultural Institute, Dunsinca Research Centre, 1971. 7p. (Research report).

WOOLFORD, M.K. 1972. Some aspects of the microbiology and biochemistry of silage making. Herb. Abstr.,42(2):105111 (Review article).

Recebido em: 23/12/97

Aceito em: 09/09/98 